\title{
Effects of Water Hardness on Dyeing of Cotton Fabrics with Different Types of Reactive Dyes and Shade Percentages
}

\author{
Mahbubur Rahman, Azizul Islam, Jagannath Biswas \\ Department of Textile Engineering, Green University of Bangladesh, Dhaka, Bangladesh \\ Email address: \\ mahbub.tex@green.edu.bd (M. Rahman), azizul.tex@green.edu.bd (A. Islam),jbiswas.tex@green.edu.bd (J. Biswas)
}

\section{To cite this article:}

Mahbubur Rahman, Azizul Islam, Jagannath Biswas. Effects of Water Hardness on Dyeing of Cotton Fabrics with Different Types of Reactive Dyes and Shade Percentages. International Journal of Materials Science and Applications. Vol. 5, No. 6, 2016, pp. 254-260. doi: 10.11648/j.ijmsa.20160506.14

Received: September 11, 2016; Accepted: September 21, 2016; Published: October 27, 2016

\begin{abstract}
This research was investigated the influence of water hardness on dyeing of cotton fabric with three types of reactive dyes (Synozol, Ramazol and Setazol). The effects of various fastness (color fastness to wash, abrasion test, Rubbing test and Perspiration test) properties of dyes were also studied and reported in this paper in details. Single color (Blue) is used for the shade of $1 \%$ and $2 \%$ and varied water hardness of $120 \mathrm{ppm}, 70 \mathrm{ppm}$ and $9 \mathrm{ppm}$ respectively. The main objective of this paper was to find out the parameters of various fastness properties at different range of water hardness in the application of different types of reactive dyes. It is visualized that different amount of water hardness showed in different fastness for using three types of reactive dyes having shade of $1 \%$ and $2 \%$. We reported that water hardness up to $9 \mathrm{ppm}$, for using three types of reactive dyes showed excellent wash fastness and it deteriorates with increasing hardness. Setazol $1 \% \& 2 \%$, showed highest abrasion resistance at 9 ppm water hardness compare to other dyes at higher water hardness. Rubbing test result also showed very good for 9 ppm water hardness in three reactive dyes irrespective of shade percentage. The perspiration test result is good at $9 \mathrm{ppm}$ water hardness for all types of reactive dyes with all shade percentages.
\end{abstract}

Keywords: Water Hardness, Fastness, Precipitation, Shade Percentage, Perspiration

\section{Introduction}

In the textile wet process, water quality plays a significant role in determining the final shades of the products, consistency and production efficiency. One of the essential factors in influencing the dye house water quality is its hardness, which is defined as the presence of soluble calcium and magnesium salts in the water and expressed in the form of $\mathrm{CaCO}_{3}$ equivalent. It is reported that the existence of hardness in water can cause dye precipitation and the precipitates can further promote dye aggregations, which result in color specks and loss of depth [1]. During the time of textile processing, the water hardness may vary due to metal content of some chemicals used in the textile wet processing, i.e. salts or electrolytes and also for the metal contamination in the textiles to be processed. The main sources of water for the textile industries in Bangladesh are collected from municipal water or deep tube well. Most of the textile wet processing industries is using Water Treatment Plant (WTP) to minimize the water hardness to an optimum level. They also use various chemicals depending on the types of wet processing employed (i.e. pre-treatment, dyeing, finishing, printing) to avoid the negative effects of remaining hardness of water. Even though the industries are facing lots of difficulties for water hardness, this is due to the poor performance of water softening plant, sequestering agent and inaccurate calculation of hardness in bath water. Maximum industries in Bangladesh consider only the hardness comes from water, but they do not consider the negative impacts of the chemicals and substrates that may contain the metal salts as impurities [2]. Textile coloration includes number of (steps) from Scouring/Bleaching to finish dyed or printed fabric or finished garment. The raw material used in the major quantity in almost every stage is water. Also, this is the main requirement in washing/laundering of garments or home furnishing products. Hence, it is very essential to do use proper water. Water from almost all sources bears various types of contaminations like, Calcium \& Magnesium (hardness), Heavy Metals (Iron, Copper, manganese etc.), Aluminum, Chlorine, various anions (Sulphide, Fluoride etc.), sediments, Clay, Suspended Matter, Acid, Alkali \& Buffer, Oil \& Grease, Dissolved Solids. The 
soap associates with the metals to form sticky soap curd. The substrate is coated with this curd that may prevent removal of soil and to some extent microorganism. The microorganism may cause odor by developing harmful bacteria. Moreover, the deposit may result harsh hand feeling and stiffness is amplified [3]. Although, several substitutes are getting into consideration, water is unquestionably the most suitable as dyeing medium. So, the quality of dyeing is vastly relying on quality of water. Throughout the time there have been lots of studies \& works to assess \& standardize dye house quality, however chronologically the water quality is degrading so alarmingly that dye houses are required to be more conscious about this [4]. Water, the most common and vital solvent for wet processing, such as dyeing, printing, rinsing, sizing, desizing, finishing, bleaching and other purposes, has a great impact over textile processes. The extent to which the presence of impurities affects the boiler depends on the concentration of the impurities in the water. Therefore, the quality of water should be necessarily maintained [5]. Shade deviation can be caused by chlorine contamination of water. This can cause color loss for many types of dyestuff. Uneven shade can also be caused by metal such as iron, copper and other metals [6]. As the textile industries, consume large volume of water and produces waste water in proportionate order. Moreover, the dyes used in textile wet processing are important sources of environmental pollution. It poses severe problems because of its strong color, high COD, BOD and low biodegradability [7]. Hardness creates many other adverse effects in wet processing. The textile dyes for each fiber are considered to have low solubility in water and these become more complicated to dissolve in very hard water. Due to inadequate solubility the dye-shade becomes weaker and may also produce spots on the dyed fabric. Further on heating or on coming in interaction with alkalis during dyeing and soaping, calcium and magnesium ions are precipitated on fabrics as whitish carbonates and hydroxide particles [8]. Major amount of the water is used for wet processing of textiles (i.e. $60 \%$ to $70 \%$ ). Humidification of spinning and weaving sheds require about 5 to $10 \%$ water. Generally the amount varies from 125 liters to 200 liters of water per $\mathrm{Kg}$ of cloth produced [9]. Water hardness is a main factor in the achievement of the washing process in areas of the world where hard water is present. However, the effects of water hardness on precipitate formation, foamability, surface tension, detergency and properties of the washed fabric using some common surfactant species have not been systematically examined in the same experimental process [10].

Hardness in laundry water is a complicated because the minerals that cause it interfere with the cleaning action of soaps and detergents. Surfactant molecules compose the part of the detergent mixture that does the actual cleaning work. In most laundry detergents, the major surfactant used is an anionic surfactant. These surfactants are very efficient at drawing oily materials and oil/clay soil into emulsion in the wash water [11].

In this study, it was investigated the effects of water hardness on three types of reactive dyes (Synozol, Ramazol and Setazol). The effects of various fastness (color fastness to wash, abrasion fastness, perspiration \& rubbing fastness) properties of dyes were also studied and reported in this paper in detail. Moreover, we tried to find the amount of water hardness for which excellent fastness properties could be achieved.

\section{Materials and Methods}

\subsection{Materials}

Scoured and bleached optical brightener free $97 \%$ cotton $\&$ $3 \%$ lycra knitted fabric with GSM $160 \mathrm{~g} / \mathrm{m}^{2}$, count $26(\mathrm{Ne})$ was used for dyeing. A range of commercial reactive dyes from different manufacturers were used in the experimental work is shown in Table 1.

Table 1. List of commercial dyes used in the experiment for dyeing.

\begin{tabular}{lll}
\hline Serial No. & Brand Name & Dyes Name \\
\hline 01 & Synozol & Blue(KHL) \\
02 & Ramazol & Blue(RSPL) \\
03 & Setazol & Blue(RSPL) \\
\hline
\end{tabular}

The chemical and auxiliaries used such as Soda Ash, Glauber salt, leveling agent, Sequestering agent and Wetting agent were of commercial grade.

\subsection{Equipment}

i). Dyeing was carried out on Lab Dyer 212 machine which is from India and made by the company of MAG Solvics Private Limited.

ii). The abrasion test is carried out in Martindale abrasion tester.

iii). Color fastness to wash test is carried out in Lab TEC (Taiwan)

iv). Color fastness to Perspiration is carried out in Perspirometer, Italy)

v). Color fastness to Rubbing is carried out in Crock Master Tester (USA).

\subsection{Methods}

Fastness Test:

Color fastness to wash test was done by a wash fastness tester (Model: MAG-G- C0356, Origin: INDIA) according to ISO 105 C06 A2S method.

Abrasion Test:

Abrasion test was carried out with the help of Martindale Abrasion Tester (Model: MAG- C0701, Origin: INDIA) according to ASTM D 4966-98(2004).

Rubbing Test:

Rubbing test was done according to ISO $105 \times 12: 2001$ method by a Crock Master Tester (Origin: USA).

\section{Perspiration Test:}

Perspiration test was done according to ISO 105-E04 or GB/T3922 method by a Perspirometer Tester (Origin: ITALY). 


\subsection{Working Procedure}

At first we collected our sample and calculate the chemicals and auxiliaries according to the recipe for the dyeing of the sample. Then we kept all the chemicals and auxiliaries in the dye pot and set it in the lab dyeing machine. The temperature was gradually raised at $3^{\circ} \mathrm{C} / \mathrm{min}$ and fixed it $80^{\circ} \mathrm{C}$. Dyeing was carried out for $60 \mathrm{~min}$. After dyeing the fabric, it was soaped with $1.5 \mathrm{cc} / 1$ soaping agent and washed again with cold water. Finally, the sample was washed again with hot water and it was dried.

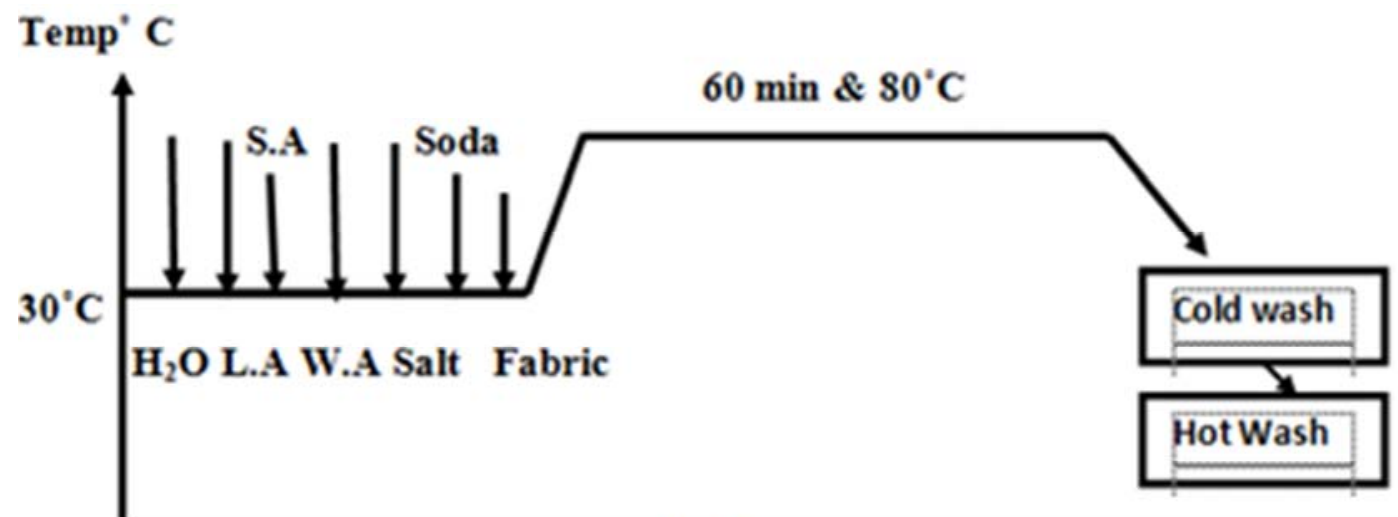

\section{Time in Min}

Figure 1. Dyeing curve of cotton fabric with reactive dye.

\subsection{Recipe}

Table 2. Recipe of cotton dyeing with Reactive dyes.

\begin{tabular}{|c|c|c|c|c|c|c|c|c|c|c|c|}
\hline Dyes Name & $\begin{array}{l}\text { W. H } \\
\text { (PPM) }\end{array}$ & Shade\% & $\begin{array}{l}\text { G. S } \\
\text { (g/l) }\end{array}$ & $\begin{array}{l}\text { S. Ash } \\
\text { (g/l) }\end{array}$ & $\begin{array}{l}\text { S. Agent } \\
\text { (cc/l) }\end{array}$ & $\begin{array}{l}\text { L.A } \\
\text { (cc/l) }\end{array}$ & $\begin{array}{l}\text { W.A } \\
\text { (cc/l) }\end{array}$ & $\begin{array}{l}\text { Time } \\
\text { (min.) }\end{array}$ & $\begin{array}{l}\text { Temp } \\
\left({ }^{\circ} \mathrm{C}\right)\end{array}$ & PH & M:L \\
\hline Synozol & $\begin{array}{l}120 \\
70 \\
9\end{array}$ & 1 & 30 & 12 & 1 & 2 & 1 & 80 & 60 & $11-12$ & $1: 15$ \\
\hline Synozol & $\begin{array}{l}120 \\
70 \\
9 \\
120\end{array}$ & 2 & 30 & 12 & 1 & 2 & 1 & 80 & 60 & $11-12$ & $1: 15$ \\
\hline Remazol & $\begin{array}{l}70 \\
9 \\
120\end{array}$ & 1 & 30 & 12 & 1 & 2 & 1 & 80 & 60 & $11-12$ & $1: 15$ \\
\hline Remazol & $\begin{array}{l}70 \\
9\end{array}$ & 2 & 30 & 12 & 1 & 2 & 1 & 80 & 60 & $11-12$ & $1: 15$ \\
\hline Setazol & $\begin{array}{l}120 \\
70 \\
9\end{array}$ & 1 & 30 & 12 & 1 & 2 & 1 & 80 & 60 & $11-12$ & $1: 15$ \\
\hline Setazol & $\begin{array}{l}120 \\
70 \\
9\end{array}$ & 2 & 30 & 12 & 1 & 2 & 1 & 80 & 60 & $11-12$ & $1: 15$ \\
\hline
\end{tabular}

\section{Results and Discussions}

\subsection{Wash Fastness Test}

Table 3 indicates standard grading parameters of wash fastness (color change) and graphical representation of table 4 is shown in Figure 2. From the table 4, it could be seen that water hardness up to $9 \mathrm{ppm}$ for all types of reactive dyes showed excellent wash fastness and it changed by increasing of water hardness. Wash fastness result shows inferior properties for all types of dyes at $120 \mathrm{ppm}$ water hardness in the $1 \%$ and $2 \%$ shade. Wash fastness shows average result in case of $70 \mathrm{ppm}$ water hardness in all types of dyes and shade percentages. This is due to the presence of higher amount of metallic ion in water containing $70 \mathrm{ppm} \& 120 \mathrm{ppm}$ hardness which may interact with dye stuff [8].

Table 3. Standard grading parameters of wash fastness.

\begin{tabular}{lll}
\hline Sl. No. & Grade & Meaning \\
\hline 01 & 1 & Very poor \\
02 & $1-2$ & Poor \\
03 & 2 & Fair \\
04 & $2-3$ & Slightly Fair \\
05 & 3 & Moderate \\
06 & $3-4$ & Good \\
07 & 4 & Very good \\
08 & $4-5$ & Excellent \\
09 & 5 & Outstanding \\
\hline
\end{tabular}




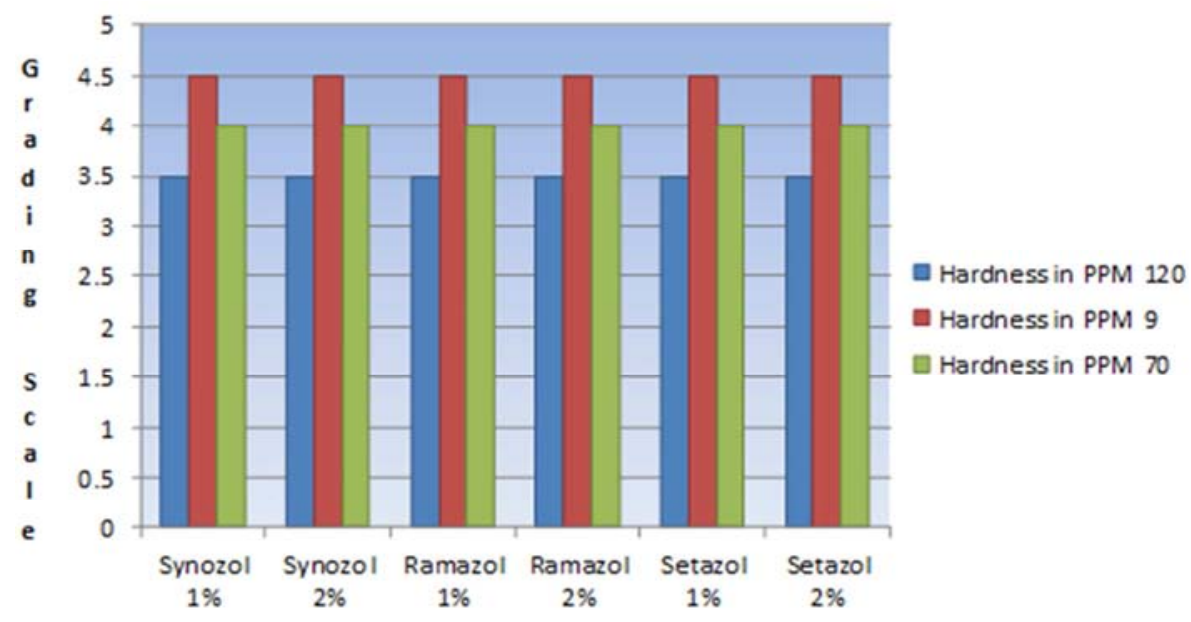

Figure 2. Effect of water hardness on color fastness to wash.

Table 4. Result of wash fastness test (color change).

\begin{tabular}{|c|c|c|c|c|}
\hline S.L & Dyes \& Shade\% & Water Hardness (PPM) & Grade & Remarks \\
\hline \multirow{3}{*}{1} & \multirow{3}{*}{$\begin{array}{l}\text { Synozol } \\
1 \%\end{array}$} & 120 & $3 / 4$ & Good \\
\hline & & 70 & 4 & Very good \\
\hline & & 9 & $4 / 5$ & Excellent \\
\hline \multirow{3}{*}{2} & \multirow{3}{*}{$\begin{array}{l}\text { Synozol } \\
2 \%\end{array}$} & 120 & $3 / 4$ & Good \\
\hline & & 70 & 4 & Very Good \\
\hline & & 9 & $4 / 5$ & Excellent \\
\hline \multirow{3}{*}{3} & \multirow{3}{*}{$\begin{array}{l}\text { Remazol } \\
1 \%\end{array}$} & 120 & $3 / 4$ & Good \\
\hline & & 70 & 4 & Very good \\
\hline & & 9 & $4 / 5$ & Excellent \\
\hline \multirow{3}{*}{4} & \multirow{3}{*}{$\begin{array}{l}\text { Remazol } \\
2 \%\end{array}$} & 120 & $3 / 4$ & Good \\
\hline & & 70 & 4 & Very Good \\
\hline & & 9 & $4 / 5$ & Excellent \\
\hline \multirow{3}{*}{5} & \multirow{3}{*}{$\begin{array}{l}\text { Setazol } \\
1 \%\end{array}$} & 120 & $3 / 4$ & Good \\
\hline & & 70 & 4 & Very good \\
\hline & & 9 & $4 / 5$ & Excellent \\
\hline \multirow{3}{*}{6} & \multirow{3}{*}{$\begin{array}{l}\text { Setazol } \\
2 \%\end{array}$} & 120 & $3 / 4$ & Good \\
\hline & & 70 & 4 & Very Good \\
\hline & & 9 & $4 / 5$ & Excellent \\
\hline
\end{tabular}

\subsection{Abrasion Test}

Table 5 shows the abrasion test results and graphical representation shows in figure 3 . Setazol $1 \% \& 2 \%$, showed highest abrasion resistance at $9 \mathrm{ppm}$ water hardness in three types of reactive dyes. But other types of reactive dyes at 9 ppm water hardness abrasion resistance change a little. When water hardness increases (70 ppm and $120 \mathrm{ppm})$, the abrasion resistance property fall for three types of reactive dyes with shade $1 \%$ and $2 \%$ than 9 ppm hardness. Tushar et.al. also reported in their paper that the presence of large volume of metallic ion in water containing higher ppm of water hardness which may interact with fabrics [8]. After all, it may visualize that abrasion resistance is overall good for three types of reactive dyes in case of various water hardness. The wear index can be calculated from the equation below.

$$
\text { Wear Index }=\frac{\text { Weight Loss } \times 1000}{\text { Total No.of Cycle }}
$$

Table 5. Result of abrasion test.

\begin{tabular}{llllll}
\hline Dyes \& Shade\% & water Hardness & Sample wt. before Abrasion (mg) & Sample wt. after Abrasion (mg) & Wt. Loss in (mg) & Wear Index \\
\hline Synozol 1\% & 120 & 173 & 166 & 7 & 3.5 \\
Synozol 2\% & 120 & 169 & 161 & 8 & 7 \\
Ramazol 1\% & 120 & 171 & 164 & 12 & 3.0 \\
Ramazol 2\% & 120 & 169 & 157 & 9 & 6.0 \\
Setazol 1\% & 120 & 171 & 162 & 6 & \\
Setazol 2\% & 120 & 170 & 164 & 7 & 3.5 \\
Synozol 1\% & 70 & 172 & 165 & 6 & 3.5 \\
Synozol 2\% & 70 & 172 & 166 & 11 & 3.0 \\
Ramazol 1\% & 70 & 172 & 161 & 12 & 5.5 \\
Ramazol 2\% & 70 & 177 & 165 & 7 & 3.0 \\
Setazol 1\% & 70 & 169 & 162 & & 3.5 \\
\hline
\end{tabular}




\begin{tabular}{|c|c|c|c|c|c|}
\hline Dyes \& Shade\% & water Hardness & Sample wt. before Abrasion (mg) & Sample wt. after Abrasion (mg) & Wt. Loss in (mg) & Wear Index \\
\hline Setazol $2 \%$ & 70 & 171 & 163 & 8 & 4.0 \\
\hline Synozol 1\% & 9 & 171 & 163 & 8 & 4.0 \\
\hline Synozol 2\% & 9 & 170 & 162 & 8 & 4.0 \\
\hline Ramazol 1\% & 9 & 173 & 163 & 10 & 5.0 \\
\hline Ramazol 2\% & 9 & 170 & 164 & 6 & 3.0 \\
\hline Setazol $1 \%$ & 9 & 171 & 167 & 4 & 2.0 \\
\hline Setazol $2 \%$ & 9 & 171 & 166 & 5 & 2.5 \\
\hline
\end{tabular}

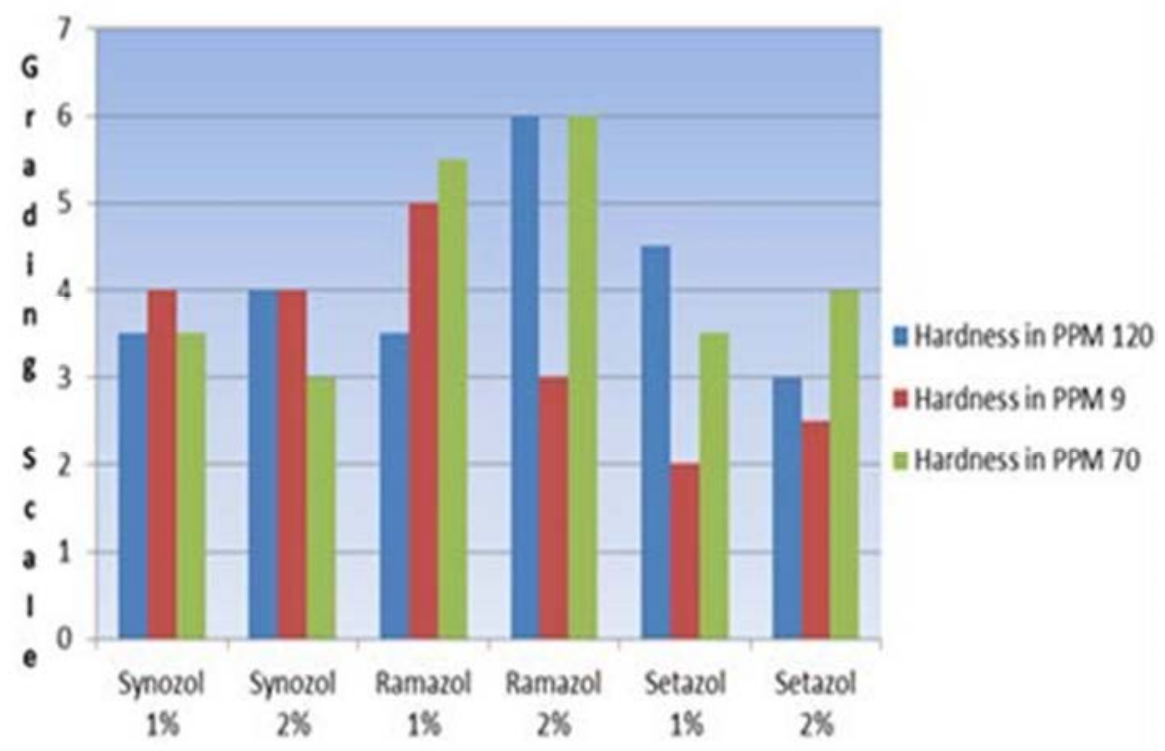

Figure 3. Effect of water hardness on abrasion fastness.

\subsection{Rubbing Test}

Table 6 indicates the standard grading parameters of rubbing test and graphical representation shows in figure 4. From Table 7, Rubbing test result showed very good for water hardness $9 \mathrm{ppm}$ in different reactive dyes with different shade percentage (Shade $1 \%$ and $2 \%$ ) like abrasion resistance. But Rubbing test results showed inferior property at $70 \mathrm{ppm}$ and $120 \mathrm{ppm}$ water hardness with different reactive dyes and different shade percentages respectively. So, it is seen that water hardness shows a significant role in rubbing test result.

Table 6. Standard grading parameters of rubbing test.

\begin{tabular}{lll}
\hline Sl. No & Grade & Remarks \\
\hline 01 & 1 & Very poor \\
02 & 2 & Poor \\
03 & 3 & Moderate \\
04 & 4 & Good \\
05 & 5 & Very good \\
\hline
\end{tabular}

Table 7. Result of rubbing test.

\begin{tabular}{lllll}
\hline S.L & Dyes \& Shade\% & Water Hardness & Grade & Remarks \\
\hline 1 & Synozol 1\% & 120 & 3 & Moderate \\
2 & Synozol 2\% $\%$ & 120 & 3 & Moderate \\
3 & Ramazol 1\% & 120 & 3 & Moderate \\
4 & Ramazol 2\% $\%$ & 3 & Moderate \\
5 & Setazol 1\% & 120 & 3 & Moderate \\
6 & Setazol 2\% & 120 & 3 & Moderate \\
7 & Synozol 1\% & 120 & 4 & Good \\
8 & Synozol 2\% & 70 & 4 & Good \\
9 & Ramazol 1\% & 70 & 4 & Good \\
10 & Ramazol 2\% & 70 & 4 & Good \\
11 & Setazol 1\% & 70 & 4 & Good \\
12 & Setazol 2\% & 70 & 4 & Good \\
13 & Synozol 1\% & 70 & 5 & Very good \\
14 & Synozol 2\% & 9 & 5 & Very good \\
15 & Ramazol 1\% & 9 & 5 & Very good \\
16 & Ramazol 2\% & 9 & 5 & Very good \\
17 & Setazol 1\% & 9 & 5 & Very good \\
18 & Setazol 2\% & 9 & 5 & Very good \\
\hline
\end{tabular}




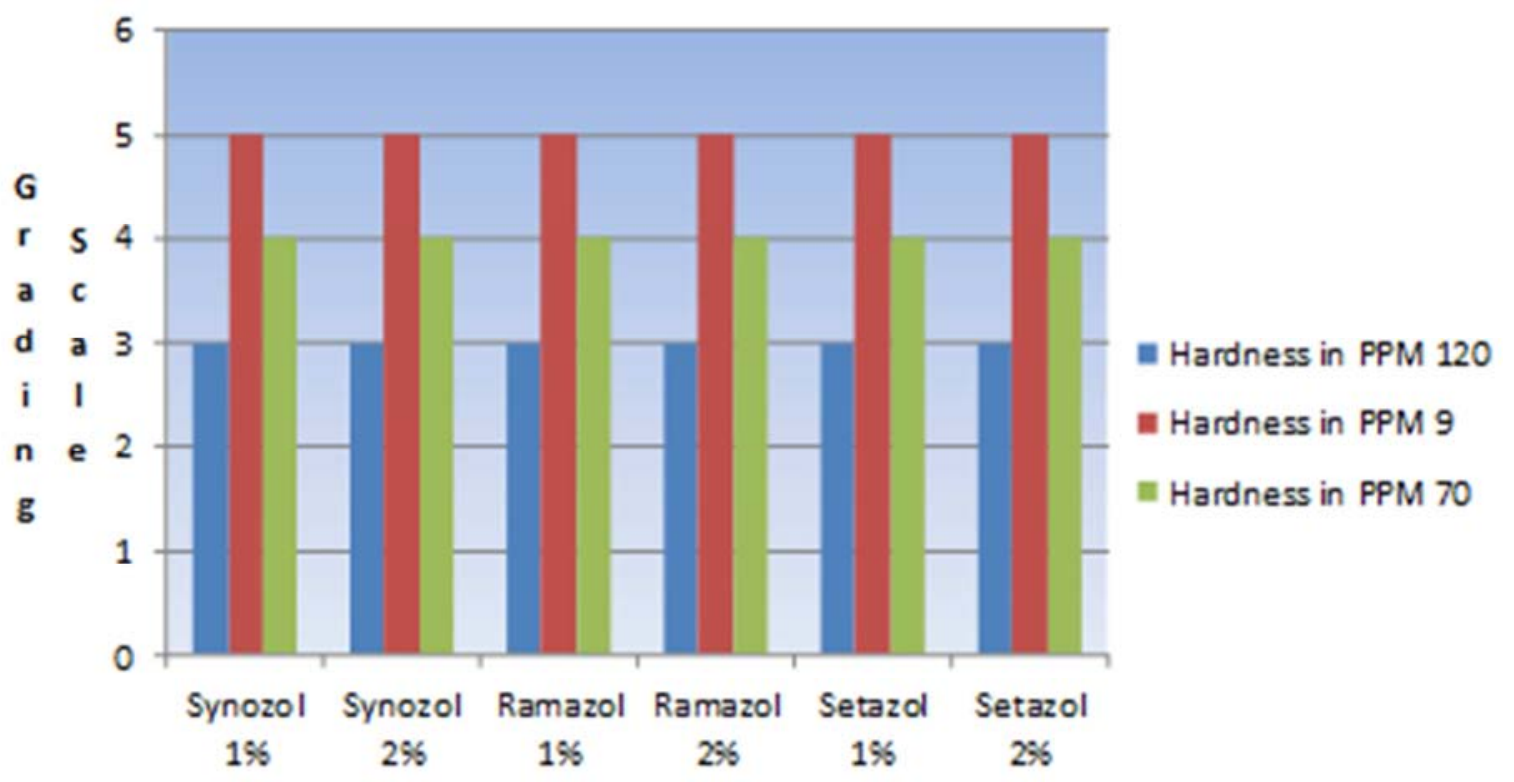

Figure 4. Effects of water hardness on rubbing test.

\subsection{Perspiration Test}

Table 8 indicates the standard grading parameters and figure 5 shows the graphical representation of perspiration test result. From table 9, Perspiration test result showed good at 9 ppm water hardness for all types of reactive dyes, which are used in this project with shade of $1 \%$ and $2 \%$. But the perspiration test result goes down when we used $70 \mathrm{ppm}$ and
$120 \mathrm{ppm}$ water hardness for three types of dyes and different shade percentages. This is due to the presence of higher amount of metallic ion in water containing $70 \mathrm{ppm} \& 120 \mathrm{ppm}$ hardness which may interact with dye stuff. That is why color fastness to perspiration properties deteriorated a little bit [8]. So, it can be seen that $9 \mathrm{ppm}$ water hardness is yielding better result than $70 \mathrm{ppm}$ and $120 \mathrm{ppm}$ water hardness.

Table 8. Grading scale -grey scale for assessing staining (including half steps).

\begin{tabular}{lll}
\hline SI. No. & Grade & Remarks \\
\hline 01 & 1 & Very poor \\
02 & 2 & Poor \\
03 & 3 & Moderate \\
04 & 4 & Good \\
05 & 5 & Very good \\
\hline
\end{tabular}

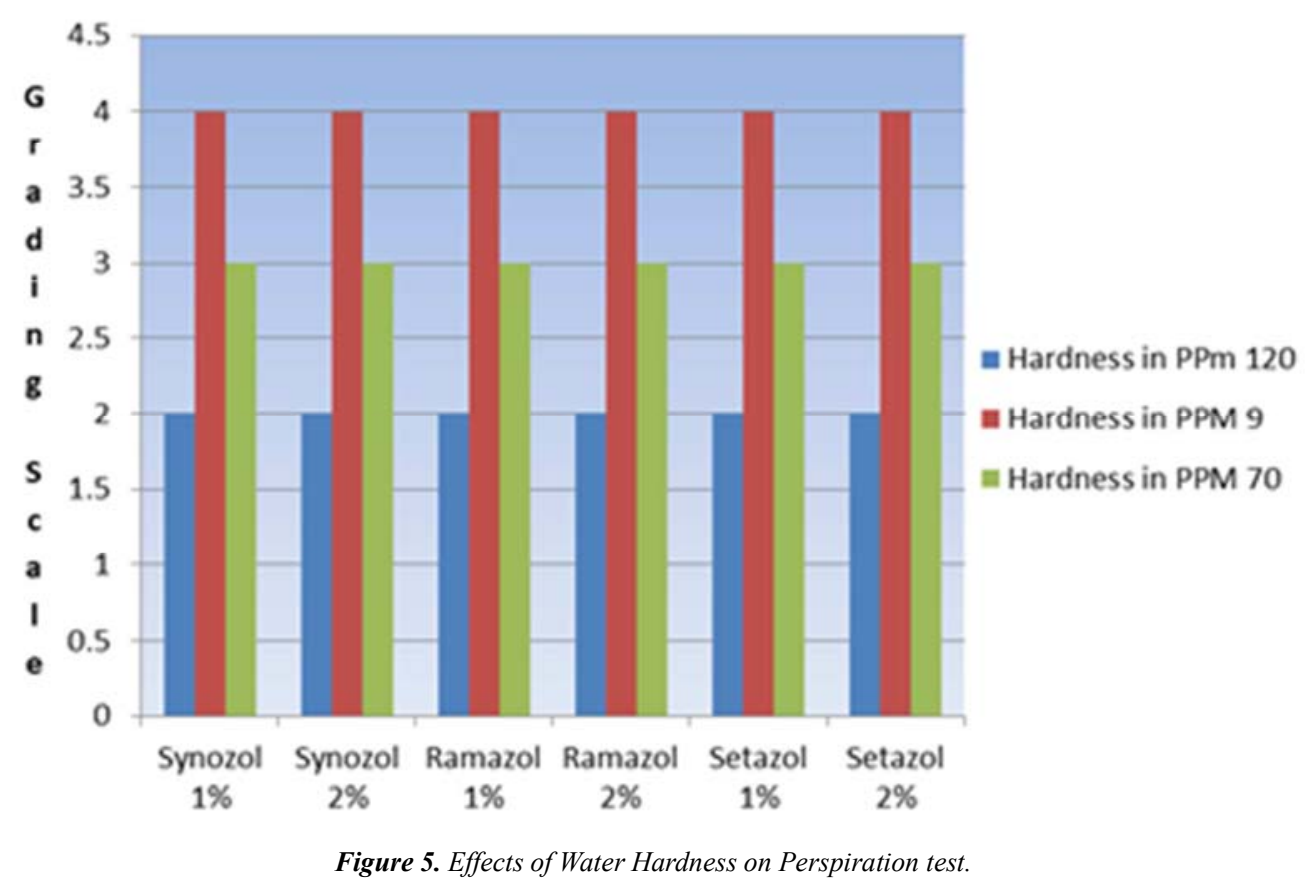


Table 9. Result of perspiration test.

\begin{tabular}{lllll}
\hline S.L & Dyes \& Shade\% & Water Hardness & Grade & Remarks \\
\hline 1 & Synozol 1\% & 120 & 2 & Poor \\
2 & Synozol 2\% & 120 & 2 & Poor \\
3 & Ramazol 1\% & 120 & 2 & Poor \\
4 & Ramazol 2\% $\%$ & 2 & Poor \\
5 & Setazol 1\% & 120 & 2 & Poor \\
6 & Setazol 2\% & 120 & 3 & Poor \\
7 & Synozol 1\% & 120 & 3 & Moderate \\
8 & Synozol 2\% & 70 & 3 & Moderate \\
9 & Ramazol 1\% & 70 & 3 & Moderate \\
10 & Ramazol 2\% & 70 & 3 & Moderate \\
11 & Setazol 1\% & 70 & 3 & Moderate \\
12 & Setazol 2\% & 70 & 4 & Moderate \\
13 & Synozol 1\% & 70 & 4 & Good \\
14 & Synozol 2\% $\%$ & 4 & Good \\
15 & Ramazol 1\% & 9 & 4 & Good \\
16 & Ramazol 2\% & 9 & 4 & Good \\
17 & Setazol 1\% & 9 & 4 & Good \\
18 & Setazol 2\% $\%$ & 9 & Good \\
\hline
\end{tabular}

\section{Conclusion}

This research was investigated the influence of water hardness on different types of reactive dyes on cotton fabrics with different shade percentages. The results showed that an increases amount of water hardness had an effect on the visual color yields of the reactive dyes obtained on cotton. It is visualized that different amount of water hardness showed in different fastness for using three types of reactive dyes having shade of $1 \%$ and $2 \%$. We reported that water hardness up to 9 ppm, for using three types of reactive dyes showed excellent wash fastness and it deteriorates with increasing hardness. Setazol $1 \%$ \& 2\%, showed highest abrasion resistance at 9 ppm water hardness compare to other dyes at higher water hardness. Rubbing test result also showed very good for 9 ppm water hardness in three reactive dyes irrespective of shade percentage. The perspiration test result is good at 9 ppm water hardness for all types of reactive dyes with all shade percentages, which are used in this project. It is clearly observed that water hardness plays an important role in textile wet processing for fastness properties. So, it is required to maintain the water quality up to an optimum level of water hardness for producing quality products.

Abbreviation used in this paper:

$[\mathrm{g} / \mathrm{gm}=$ gram, $\mathrm{l}=$ liter, $\min .=$ minutes, W.H = Water Hardness, G.S= Glauber Salt, S. Ash = Soda Ash, S. Agent $=$ Sequestering Agent, L.A = Leveling Agent, W.A = Wetting Agent]

\section{References}

[1] K. Chi-wai, "Effect of water hardness on acid dyeing with silk", AUTEX Research Journal, Vol. 08, No2, June 2008.

[2] M. G. Uddin, A. S. M. Atiquzzaman, "Estimation of Total Hardness of Bath Water in Knit Dye Houses in Bangladesh and Study of Its Effects", International Journal of Textile Science 2014, 3 (4): 59-63 DOI: 10.5923/j.textile.20140304.01
[3] P. N. PALANISAMY and S. K. KAVITHA, "An Assessment of the Quality of Groundwater in a Textile Dyeing Industrial Area in Erode City, Tamilnadu, India”, E-Journal of Chemistry, 2010, 7 (3), 1033-1039.

[4] E. Khalil, J. Sarkar, "Effect of Hardness of Water on Fixation and Total Wash off Percentage of Reactive Dyes When Applied to Cellulosic Fiber" International Journal of Scientific and Research Publications, Volume 4, Issue 9, September 2014, ISSN 2250-3153.

[5] M. Begum, M. Hossen and A. Khatton, "Water characteristics suitability for textile wet processing and its remedy measures", Bangladesh Jute Research Institute, January 16, 2009.

[6] A. Delituna, "Effects of water hardness on color obtained in dyeing of polyester microfiber", INTERNATIONAL SCIENTIFIC CONFERENCE, 19-20 November 2010, GABROVO.

[7] S. A. Paul, S. K. Chavan and S. D. Khambe,"Studies on characterization of textile industrial waste water in solapur city”, Int. J. Chem. Sci.: 10 (2), 2012, 635-642, ISSN 0972-768X.

[8] T.A. Shinde, R. Marathe and V. A. Dorugade, "Effect of water hardness on reactive dyeing of cotton", International Journal on Textile Engineering and Processes, ISSN: 2395-3578, Vol 1, Issue 4, October 2015.

[9] P. B. Nangare, D. V. Wadkar and R. S. Karale, "Impact of textile industry on ground water quality with special reference to ichalkaranji city, m. s., (india)", Journal of Environmental Research And Development, Vol. 2 No. 4, April-June 2008.

[10] Keiko Gotoh, Kaori Horibe, Yang Mei and Toshiyuki Tsujisaka, "Effects of water hardness on textile detergency performance in aqueous cleaning system", Journal of Oleo Science, J. Oleo Sci. 65 (2) 123-133, 2016.

[11] Konstadinos Abeliotis, Cevza Candan, Caroline Amberg, Ada Ferri, Miguel Osset, Jeremy Owens and Rainer Stamminger, "Impact of water hardness on consumers' perception of laundry washing result in five European countries", International Journal of Consumer Studies 39, 60-66, (2015). 